\title{
Minocycline Protection of Neomycin Induced Hearing Loss in Gerbils
}

\author{
Alan M. Robinson, ${ }^{1}$ Irena Vujanovic, ${ }^{1}$ and Claus-Peter Richter ${ }^{1,2,3}$ \\ ${ }^{1}$ Department of Otolaryngology-Head and Neck Surgery, Feinberg School of Medicine, Northwestern University, \\ Chicago, IL 60611, USA \\ ${ }^{2}$ Department of Biomedical Engineering, Northwestern University, Evanston, IL 60208, USA \\ ${ }^{3}$ Department of Communication Sciences and Disorders, The Hugh Knowles Center, Northwestern University, \\ Evanston, IL 60208, USA \\ Correspondence should be addressed to Alan M. Robinson; a-robinso2@northwestern.edu
}

Received 6 October 2014; Revised 20 March 2015; Accepted 21 March 2015

Academic Editor: Paul M. Tulkens

Copyright (C) 2015 Alan M. Robinson et al. This is an open access article distributed under the Creative Commons Attribution License, which permits unrestricted use, distribution, and reproduction in any medium, provided the original work is properly cited.

\begin{abstract}
This animal study was designed to determine if minocycline ameliorates cochlear damage is caused by intratympanic injection of the ototoxic aminoglycoside antibiotic neomycin. Baseline auditory-evoked brainstem responses were measured in gerbils that received $40 \mathrm{mM}$ intratympanic neomycin either with $0,1.2$, or $1.5 \mathrm{mg} / \mathrm{kg}$ intraperitoneal minocycline. Four weeks later auditoryevoked brainstem responses were measured and compared to the baseline measurements. Minocycline treatments of $1.2 \mathrm{mg} / \mathrm{kg}$ and $1.5 \mathrm{mg} / \mathrm{kg}$ resulted in significantly lower threshold increases compared to $0 \mathrm{mg} / \mathrm{kg}$, indicating protection of hearing loss between $6 \mathrm{kHz}$ and $19 \mathrm{kHz}$. Cochleae were processed for histology and sectioned to allow quantification of the spiral ganglion neurons and histological evaluation of organ of Corti. Significant reduction of spiral ganglion neuron density was demonstrated in animals that did not receive minocycline, indicating that those receiving minocycline demonstrated enhanced survival of spiral ganglion neurons, enhanced survival of sensory hairs cells and spiral ganglion neurons, and reduced hearing threshold elevation correlates with minocycline treatment demonstrating that neomycin induced hearing loss can be reduced by the simultaneous application of minocycline.
\end{abstract}

\section{Introduction}

Aminoglycoside antibiotics are effective antibacterial agents that generate ototoxic metabolic products. Systemic administration can lead to destruction of vestibular and cochlear hair cells, causing disequilibrium and/or hearing loss [1-12]. Members of the aminoglycoside family differ in their relative toxicity vestibular and cochlear hair cells, with neomycin and kanamycin A preferentially causing cochlear damage, while streptomycin, gentamicin, amikacin, and tobramycin are preferentially vestibulotoxic [13-15]. Given this toxicity, aminoglycoside treatment for bacterial infections is performed judiciously in developed countries, often being used topically or as the drug of last resort but they are used systemically in underdeveloped countries primarily because they are inexpensive [13].
Ideally their use should be better controlled; however, the addition of an inexpensive agent that ameliorates ototoxicity may be a viable means to prevent unnecessary hearing loss and vestibular disorders. Such an agent would need to suppress the mechanism of ototoxicity. Recent advances have been made in elucidating the mechanism of toxicity to hair cells and have demonstrated substantial apoptosis within twelve hours of exposure to aminoglycoside in guinea pig [16] and initiated within three hours of noise exposure [17]. Knowledge of the mechanistic details of apoptotic induction now provides us with steps in the pathway at which a pharmacologic agent could potentially act to afford inhibition of hair cell death [18-23].

Hair cell apoptosis is believed to be initiated by interference with mitochondrial protein synthesis leading to production of free oxygen radicals and activation of inducible 
nitric oxide synthetase, producing nitric oxide. Reaction of free oxygen radicals with nitric oxide creates peroxynitrite radicals that initiate the intrinsic or mitochondrial apoptosis pathway $[24,25]$. The intrinsic pathway involves proapoptotic proteins Bax and Bak which initiate release of cytochrome $\mathrm{c}$ from the mitochondria followed by caspase 9 and caspase 3 activation and cell death [26]. Initiation of the pathway is also influenced by activation of c-Jun $\mathrm{N}$ terminal kinase (JNK) and mitogen-activated protein kinase [27]. Theoretically inhibition of these events may ameliorate hair cell apoptosis.

Pharmacologic agents that inhibit hair cell apoptosis would ideally act as early on as possible in the apoptosis pathway and offer long-term protection to maximize their efficacy. Like all pharmacologic agents they would be subject to meeting the administration, distribution, metabolism, elimination (ADME) and toxicology, drug interaction, and specificity requirements required for approval by pharmaceutical agencies worldwide. Finding a new application for an already approved pharmacologic agent to be used for amelioration of hair cell apoptosis would be ideal [28]. Additionally, the apoptotic mechanism of noise-induced hair cell death appears to follow a similar mechanism, so the potential for a pharmacologic agent to treat both causes of hearing loss may be feasible [29].

Minocycline is a long-time worldwide approved inexpensive tetracycline derivative that has antibiotic, antiinflammatory, free radical scavenging and antiapoptotic induction properties [30-36]. Most pertinent to this study it has been reported to inhibit in vitro hair cell death in rat cochlear explants [37]. Therefore, minocycline was tested for its in vivo ability to ameliorate hearing loss in gerbils following intratympanic neomycin application.

\section{Methods}

2.1. Animals. Six-month-old gerbils (Meriones unguiculatus) of either sex $(60-80 \mathrm{~g})$ were used for this study and were randomly assigned to minocycline treatment groups. Animal numbers represented were $n=6, n=8$, and $n=7$ for $0 \mathrm{mg} / \mathrm{kg}, 1.2 \mathrm{mg} / \mathrm{kg}$, and $1.5 \mathrm{mg} / \mathrm{kg}$ minocycline, respectively. The human equivalent dose for $1.2 \mathrm{mg} / \mathrm{kg}$ based on the body surface area normalization method would be $1.2 \times(4 / 37)=$ $0.13 \mathrm{mg} / \mathrm{kg}$ or $7.8 \mathrm{mg}$ in a $60 \mathrm{~kg}$ human, assuming $K_{m}$ gerbil of 4 and $K_{m}$ human of 37 , where $K_{m}$ is the ratio of body mass to surface area defined in [38]. Based on body mass only the dose would be extrapolated to $1.2 \times 60=72 \mathrm{mg}$ for a $60 \mathrm{~kg}$ human. Additional 3 animals were later included for no minocycline (vehicle alone in ear) and no neomycin controls for histology. Baseline auditory-evoked brainstem responses (ABRs) were measured for the left and right ears of the gerbils.

Following baseline ABR measurements animals received a single intratympanic injection of $40 \mathrm{mM}$ neomycin (SigmaAldrich, St. Louis, MO) in Ringer's balanced lactate in the left bulla and Ringer's balanced lactate vehicle alone in the right bulla. $40 \mathrm{mM}$ neomycin was chosen based on it producing only partial hearing loss in our pilot experiments, therefore making it more likely for us to see any minocycline effect. The injection volume was approximately $150 \mu \mathrm{L}$, sufficient to fill the middle ear air space. Animals then received either $0 \mathrm{mg} / \mathrm{kg}, 1.2 \mathrm{mg} / \mathrm{kg}$, or $1.5 \mathrm{mg} / \mathrm{kg}$ intraperitoneal (IP) injection of minocycline hydrochloride (Sigma-Aldrich, St. Louis, MO) in normal saline daily, for five days. Day one minocycline injections were given immediately following baseline ABR measurements.

Four weeks after treatment, ABR measurements were performed for left and right ears of each animal. Animals were then anesthetized and sacrificed. Bullae were dissected for histological preparation and analysis of the cochleae. Animal procedures were performed in accordance with the guidelines of the National Institutes of Health and were approved by the Northwestern University Animal Care and Use Committee.

\subsection{Measuring Cochlear Function with Auditory Brainstem} Responses (ABRs). The method has been described previously [39]. Voltage commands for the stimuli were generated using a computer KPCI 3110-I/O board (Keithley Instruments Inc., Cleveland, $\mathrm{OH}$ ) inserted into a $\mathrm{PC}$ and were used to drive a Beyer DT 770Pro headphone (Beyerdynamic, Heilbronn, Germany). Tone bursts (12 ms duration, including a $1 \mathrm{~ms}$ rise/fall) with different carrier frequencies were presented at a rate of $4 \mathrm{~Hz}$. The frequency range was $1.8-50 \mathrm{kHz}$ at three steps per octave. For the experiments, the speculum of the speaker was placed directly in front of the ear canal (quasi free field). The sound pressure was measured with a real head coupler [40].

After the animals were deeply anesthetized, ABRs were obtained by subtracting ipsilateral mastoid potentials from vertex potentials measured relative to a ground electrode, which was placed in the neck. The electrodes were connected to a differential amplifier (ISO 80, WPI, Sarasota, FL). The amplifier setting was at 10,000. Further filtering (300 to $3000 \mathrm{~Hz}$ ) of the signal was obtained through a Frequency Devices filter (IP90). The sampling rate was $200 \mathrm{kHz}$, and responses to 100 stimulus presentations were averaged. ABR thresholds were defined as sound levels required for a visible wave II in the response to acoustic stimuli. The noise floor in an averaged $\mathrm{ABR}$ recording was typically $1 \mu \mathrm{V}$.

2.3. Histological Preparation. Bullae were dissected from euthanized gerbils and were fixed for two hours in $4 \%$ paraformaldehyde in Phosphate Buffered Saline (PBS, pH 7.4) at room temperature. Postdissection fixation continued overnight at $4^{\circ} \mathrm{C}$. Bullae were washed in PBS (pH 7.4) and the inner ear structures were partially exposed by limited removal of surrounding bone. Tissues were decalcified for 48 hours at $4^{\circ} \mathrm{C}$ in $4 \%$ formic acid and $2 \%$ sodium citrate, washed in PBS to remove acid and citrate, dehydrated through graded ethanol, cleared in xylene, and embedded in ParaplastXtra paraffin wax (McCormick Scientific, St. Louis, MO). Cochleae were sectioned at $10 \mu \mathrm{m}$ longitudinally to obtain midmodiolar sections mounted on glass slides, dewaxed, hydrated, stained with hematoxylin alone, and dehydrated and cover slips were mounted.

2.4. Counting of Spiral Ganglion Neurons. Quantification of spiral ganglion neurons (SGN) was performed in left ears 
TABLE 1: Shown are the numbers of animals falling within a given ABR threshold shift bin range over 6-19 kHz test range for each minocycline concentration treatment. See Figure 1 representation of threshold shifts for each treatment over the frequency range tested in the ABRs. Fisher's exact $2 \times 2$ statistical test tables for threshold shift bin ranges for pairwise combination difference tests among $0 \mathrm{mg} / \mathrm{kg}, 1.2 \mathrm{mg} / \mathrm{kg}$, and $1.5 \mathrm{mg} / \mathrm{kg}$ minocycline treatments were performed on animal numbers. Threshold shifts of $1.2 \mathrm{mg} / \mathrm{kg}$ and $1.5 \mathrm{mg} / \mathrm{kg}$ minocycline treated animals were not significantly different from each other but were significantly less than threshold shifts of the $0 \mathrm{mg} / \mathrm{kg}$ animals $(P=0.028$ one sided).

\begin{tabular}{lccc}
\hline $\begin{array}{l}\text { Threshold shift bin } \\
\text { range }(\mathrm{dB} \text { SPL })\end{array}$ & $\begin{array}{c}\text { Number of animals } \\
(0 \mathrm{mg} / \mathrm{kg})\end{array}$ & $\begin{array}{c}\text { Number of animals } \\
(1.2 \mathrm{mg} / \mathrm{kg})\end{array}$ & $\begin{array}{c}\text { Number of animals } \\
(1.5 \mathrm{mg} / \mathrm{kg})\end{array}$ \\
\hline $1-19$ & 0 & 5 & 3 \\
20 and $>20$ & 6 & 3 & 3 \\
\hline
\end{tabular}

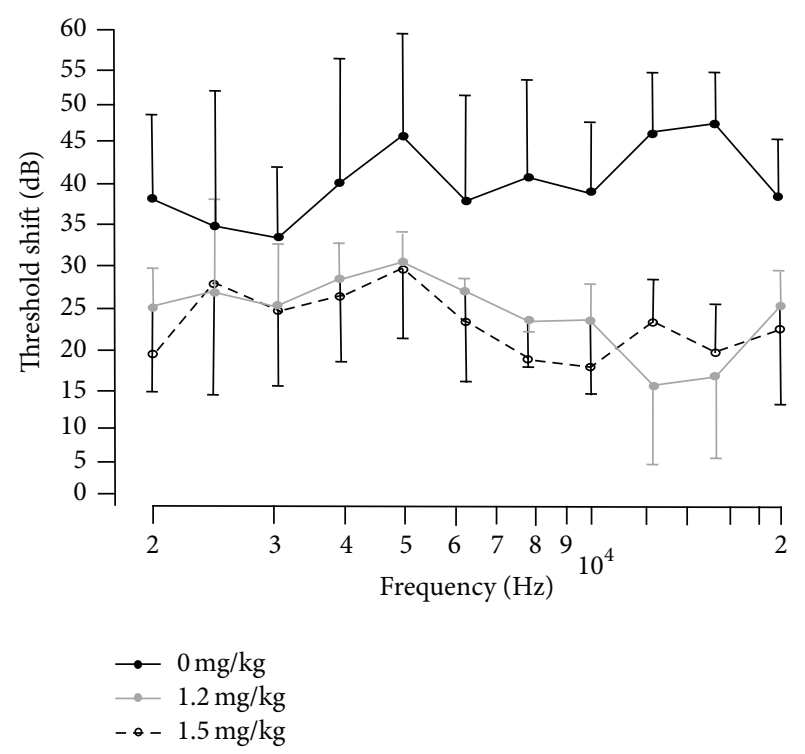

Figure 1: Auditory-evoked brainstem response (ABR) threshold shifts (left ears received transtympanic neomycin) for $0 \mathrm{mg} / \mathrm{kg}$, $1.2 \mathrm{mg} / \mathrm{kg}$, and $1.5 \mathrm{mg} / \mathrm{kg}$ I.P. minocycline treated gerbils. Plots represent subtraction of baseline (week 0) thresholds from week 4 thresholds over approximate frequency range of $2-20 \mathrm{kHz}$. In the 6-19 KHz range the threshold shifts of $1.2 \mathrm{mg} / \mathrm{kg}$ and $1.5 \mathrm{mg} / \mathrm{kg}$ minocycline treated animals were not significantly different from each other but were significantly less than threshold shifts of the $0 \mathrm{mg} / \mathrm{kg}$ animals (see Table 1 and methods for Fisher's exact statistical test of data). Error bars are standard deviation from mean threshold shifts.

to determine if there was a correlation between minocycline treatment and the respective ABR measurements. Right ear ABRs were used as internal controls to ensure that changes in the left ear ABRs were treatment specific and not systemic or due to the intratympanic injection procedure itself.

The counting was conducted as described previously [39]. In brief, ten consecutive midmodiolar sections were selected to capture images of the spiral ganglion at several different locations along the cochlea. A profile count was performed by two individuals, one blinded to the treatment groups. To do this, every spiral ganglion neuron in a cross section with a nucleus larger than $5 \mu \mathrm{m}$ and with a nucleolus was counted. The resulting significant cell overcount established by comparison of the stereological count of spiral ganglia sections was corrected for by a factor of $0.71 x$. The stereologic counting and establishing of the correction factor has been validated and published previously [39].

In addition to counting cells, the cross-sectional area of Rosenthal's canal was determined. Measurements were taken using ImageJ (Wayne Rasband, NIH, public domain software). The program's scale was calibrated and the scale setting was changed from pixels to micrometers. This conversion was accomplished by determining the number of pixels between two lines of the image of a standard slide having $10 \mu \mathrm{m}$ divisions. Area measurements were obtained by tracing the bony opening of Rosenthal's canal. The total number of pixels within a circumscribed area was calculated and converted into square millimeters.

2.5. Histological Evaluation of the Organ of Corti. Hematoxylin stained tissue sections were examined microscopically and digital images captured. The number of observations of hair cells was tallied for the minocycline treatment and corresponding cochlear turns. Ten sections for each cochlear turn were evaluated for each of three animals per minocycline treatment group and no minocycline and no neomycin control group. Cell types scored were inner hair cells (IHC), the three rows of outer hair cells $(\mathrm{OHC}) 1,2$, and 3 and the three rows of Deiters cells (DC) 1,2 , and 3, and are identified in Figure 3.

2.6. Statistical Analysis. ABR thresholds were entered into IgorPro 4 (Wavemetrics) software to generate threshold shift values by subtracting baseline thresholds from week 4 thresholds for each treatment. Threshold shift and frequency curves were plotted with standard deviations (Figure 1). For statistical analysis of the threshold shifts, Fisher's exact test was used to compare minocycline treatments for the 6$19 \mathrm{kHz}$ frequency range, where standard deviations suggested likely significance. Pairwise comparisons were made between $0 \mathrm{mg} / \mathrm{kg}$ and $1.2 \mathrm{mg} / \mathrm{kg}, 0 \mathrm{mg} / \mathrm{kg}$ and $1.5 \mathrm{mg} / \mathrm{kg}$, and $1.2 \mathrm{mg} / \mathrm{kg}$ and $1.5 \mathrm{mg} / \mathrm{kg}$ minocycline. Columns of the $2 \times 2$ contingency tables consisted of the minocylcline concentration treatment category; rows of the table consisted of the number of animals falling within threshold elevation ranges of either 1-19 dB SPL or $20 \mathrm{~dB}>20 \mathrm{~dB}$. The threshold bin range was set as the midpoint between the the $0 \mathrm{mg} / \mathrm{kg}$ threshold shift and the minocycline treated threshold shifts (Table 1).

Mean SGN densities were calculated separately for the upper base, middle, and upper middle regions of the cochlear 
turns for each animal in each treatment group and tested for statistical significance by one-way ANOVA followed by Tukey HSD test using IgorPro 4 (Wavemetrics) software. Qualitative histological examination of the upper base, middle, and upper middle regions of the cochleae was performed on SGN appearance in Rosenthal's canal and the presence or absence of hair cells in the organ of Corti.

\section{Results}

Left ears were treated with neomycin and animals received either $0,1.2$, or $1.5 \mathrm{mg} / \mathrm{kg}$ micocycline IP. At week 4 after neomycin left ear ABR thresholds were elevated from their baseline obtained at week 0 for all minocycline treatment groups (Figure 1). To quantify the overall change in ABR threshold, for each treatment group, the average threshold was calculated by averaging the threshold at the different frequencies and by subsequently subtracting the average threshold obtained before neomycin treatment to obtain a threshold shift. Average threshold shifts for the individual minocycline treatments were $40 \mathrm{~dB}$ for $0 \mathrm{mg} / \mathrm{kg}$ minocycline and $20 \mathrm{~dB}$ for both $1.2 \mathrm{mg} / \mathrm{kg}$ and $1.5 \mathrm{mg} / \mathrm{kg}$ (Figure 1). Threshold shifts for right ear controls were at or close to zero indicating that the ABR threshold elevations in the left ears were treatment specific, not systemic, or due to the intratympanic injection trauma (not shown).

As absolute thresholds beyond the speaker output limit could not be determined in most $0 \mathrm{mg} / \mathrm{kg}$ minocycline treated animals only measures below $20 \mathrm{kHz}$ were considered in the calculation of the mean threshold shifts, thereby underestimating the threshold shift in the $0 \mathrm{mg} / \mathrm{kg}$ cohort. For example, in some animals, no ABR response could be evoked for stimulus frequencies above $19 \mathrm{kHz}$, indicating a larger threshold shift than the difference between the sound level for the baseline ABR threshold and the maximum sound level of the speaker. They were deaf at those tested frequencies. Two animals in the $0 \mathrm{mg} / \mathrm{kg}$ minocycline group had no detectable thresholds above $12 \mathrm{kHz}$ which meant that they had no quantifiable thershold shift, so for statistical purposes we used Fisher's exact test as described in the methods to include these animals (Table 1). Threshold shifts of $1.2 \mathrm{mg} / \mathrm{kg}$ and $1.5 \mathrm{mg} / \mathrm{kg}$ minocycline treated animals were not significantly different (Fisher's exact test) from each other but were significantly less than threshold shifts of the $0 \mathrm{mg} / \mathrm{kg}$ animals over $6-19 \mathrm{kHz}(P=0.028$ one sided $)$.

The mean SGN densities in the upper base, middle, and upper middle regions of the left ear cochlear turns are shown in Table 2 and visually in Figure 2. Each animal in each treatment group demonstrated a significant difference by ANOVA between $0 \mathrm{mg} / \mathrm{kg}$ and $1.2 \mathrm{mg} / \mathrm{kg}$ and $0 \mathrm{mg} / \mathrm{kg}$ and $1.5 \mathrm{mg} / \mathrm{kg}$ minocycline $(P<0.05)$.

Photomicrographs of organ Corti within left ear cochleae of animals treated with neomycin and those of the corresponding untreated right ear controls demonstrate hair cell toxicity of the neomycin treatment, are shown in Figure 3, and also serve to identify cell types. Cell types within the organ of Corti were scored as ten serial tissue sections of three animals per treatment group and are represented in Figure 4.
TABLE 2: Stereoscopic SGN counts of three animals per treatment group and 30 measures per animal for each of upper basal. Middle and upper middle turns within the cochleae. Statistically significant ANOVA SGN density differences were observed between $0 \mathrm{mg} / \mathrm{kg}$ and $1.2 \mathrm{mg} / \mathrm{kg}$ minocycline and between $0 \mathrm{mg} / \mathrm{kg}$ and $1.5 \mathrm{mg} / \mathrm{kg}$ minocycline $(P<0.05)$.

\begin{tabular}{lccr}
\hline & \multicolumn{3}{c}{ Minocycline concentration } \\
$\begin{array}{l}\text { Turn within } \\
\text { cochlea }\end{array}$ & $\begin{array}{c}0 \mathrm{mg} / \mathrm{kg} \\
\text { Spiral ganglion cell density in Rosenthal's canal } \\
\text { (cells/ } \mathrm{mm}^{2} \text { ) }\end{array}$ \\
\hline Upper basal & $712 \pm 241$ & $1273 \pm 374$ & $867 \pm 193$ \\
Middle & $787 \pm 306$ & $1201 \pm 285$ & $951 \pm 315$ \\
Upper middle & $780 \pm 263$ & $1129 \pm 188$ & $920 \pm 321$ \\
$\begin{array}{l}\text { Average of all } \\
\text { turns }\end{array}$ & $759 \pm 263$ & $1203 \pm 315$ & $929 \pm 276$ \\
\hline
\end{tabular}

In the $0 \mathrm{mg} / \mathrm{kg}$ minocycline group all cochlear regions had the lowest percent of all cell types evaluated. Of particular note are the hair cells where middle and upper middle turns had the lowest percent decrease in $1.2 \mathrm{mg} / \mathrm{kg}$ and $1.5 \mathrm{mg} / \mathrm{kg}$ minocycline treatment groups, excluding controls, indicating preservation of hair cells with minocycline treatment. Control animals did not receive neomycin or minocycline and most sections had observable inner and outer hair cells.

\section{Discussion}

We show here in vivo that minocycline reduces but does not completely eliminate neomycin induced hearing loss. Furthermore, the specific significant reduction of threshold shift only spans a frequency range of $6-19 \mathrm{KHz}$, which encompasses part of the upper basal turn extending to the middle turn (Figure 1). However, it is likely that the protected frequency range extends to higher than $19 \mathrm{kHz}$ since the animals not receiving minocycline often had no measurable threshold but even in treated animals these high frequency measures are subject to significant variability due to technical constraints. Our findings are consistent with partial protection of hair cells in rat cochlea explants where maximal prevention of hair cell loss was achieved in explants treated with $100 \mu \mathrm{M}$ minocycline in combination with the ototoxic aminoglycoside gentamicin [41].

Neomycin is an ototoxic aminoglycoside and cumulative evidence shows that apoptosis of sensory hair cells is the predominant mechanism in ototoxicity, noise, and age-related hearing loss [42]. We, therefore, used the survival of hair cells and SGNs as a metric for minocycline efficacy. The end effect is likely reduced cell apoptosis conferred by minocycline. In general, as to the exact mechanism of minocycline action, no study has been able to absolutely isolate its antiapoptotic and anti-inflammatory properties, which are numerous [43]. With limited understanding [44] of the underlying mechanism(s) of action of minocycline, clinical trials have, and are being conducted to test the efficacy of minocycline in stroke, Alzheimer's disease, multiple sclerosis, spinal cord injury, amyotrophic lateral sclerosis, Huntington's disease, 


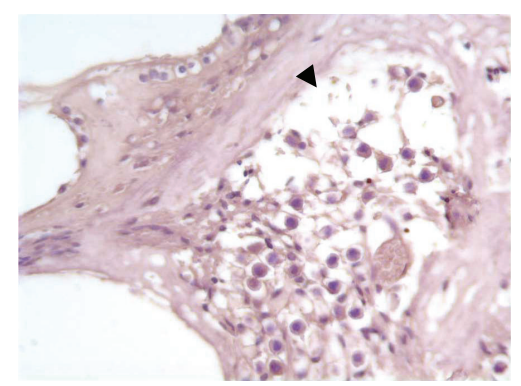

(a)

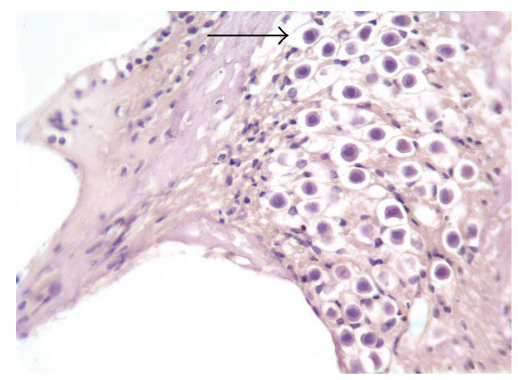

(d)

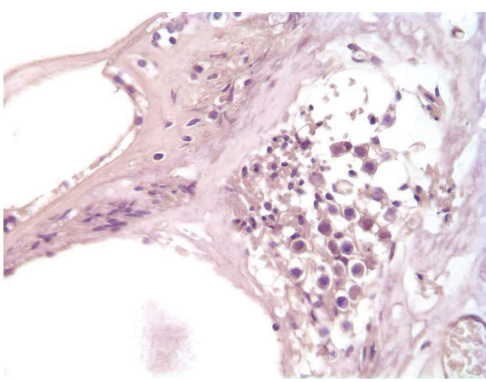

(b)

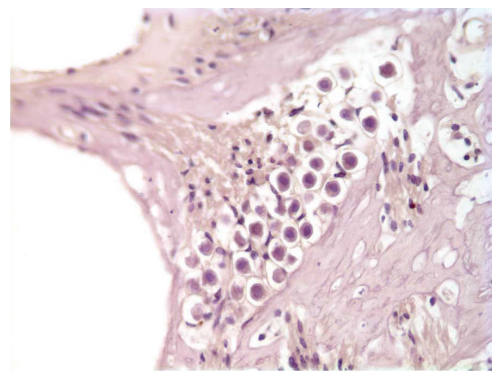

(e)

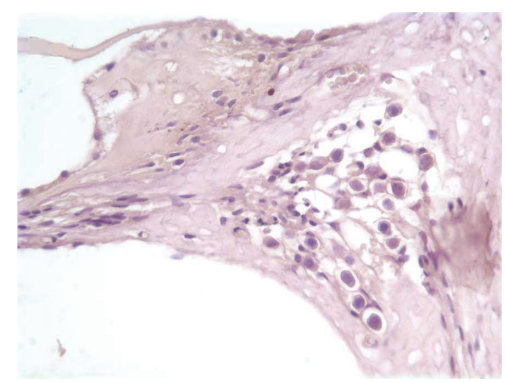

(c)

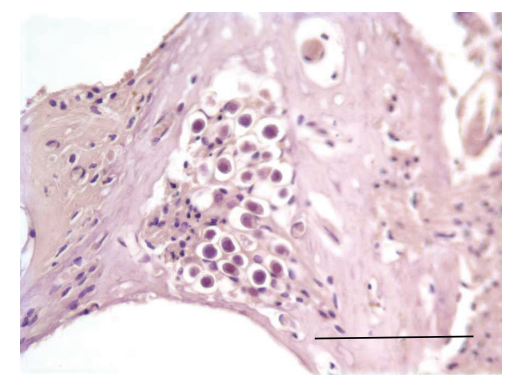

(f)

FiguRE 2: SGN within Rosenthal's canal (arrow head) of the left ear cochlea. Upper middle, middle turn, and basal turn (a, b, and c, resp.) of $0 \mathrm{mg} / \mathrm{kg}$ minocycline treatment compared to corresponding turns of $1.2 \mathrm{mg} / \mathrm{kg}$ minocycline treated animal (d, e, and f). $0 \mathrm{mg} / \mathrm{kg}$ animals show reduced SGN density (arrow head) compared to $1.2 \mathrm{mg} / \mathrm{kg}$. Arrow indicates SGN. Scale bar $=50 \mu \mathrm{m}$.

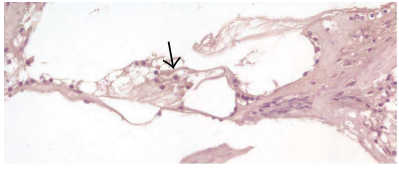

(a)

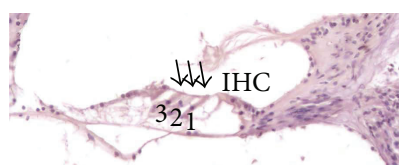

(d)

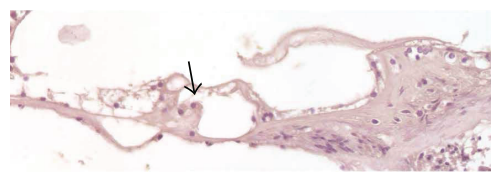

(b)

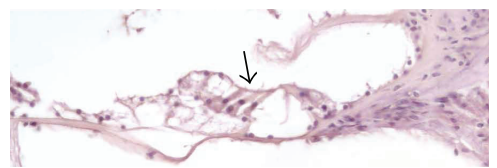

(e)

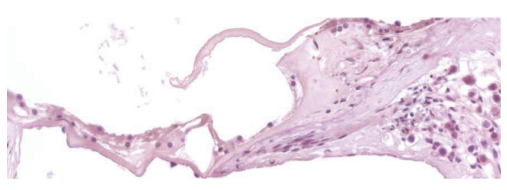

(c)

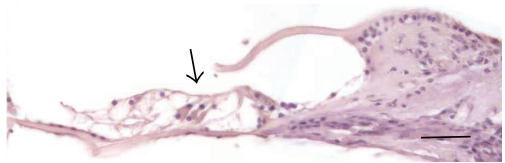

(f)

Figure 3: Organ of Corti within the left ears of $0 \mathrm{mg} / \mathrm{kg}$ minocycline treated animals ( $\mathrm{a}, \mathrm{b}$, and c); the upper middle and middle turns (a) and (b), respectively, had identifiable outer hair cells, while upper basal turns were often devoid of hair cells (c). In the corresponding right ear internal animal controls, the upper middle (d) and middle turns (f), had hair cells as the left ears did, while the upper basal turn (f) had outer hair cells, unlike the left ear. This shows that the neomycin treatment of the left ear caused hair cell loss. Panel (d) is annotated to show inner hair cell (IHC) with arrows indicating outer hair cell rows 1, 2, and 3 which lie immediately above the dark purple nuclei of Deiters cells 1, 2, and 3. Solid arrows indicate outer hair cells. Bar $=50 \mu \mathrm{m}$.

Parkinson's disease, and traumatic brain injury (TBI). The favorable tolerability and safety of minocycline combined with the need for human treatments may justify such wide ranging trials. For example, some combination of the antiapoptotic and anti-inflammatory actions of minocycline may ameliorate traumatic brain injury, with little risk.

We did not address the mechanism(s) of hair cell and SGN protection because our end point was directed at determining a late stage functional hearing benefit, which is a preliminary step in determining efficacy and minocycline dosage. Additional studies within hours of neomycin administration would be required to detect potential antiapoptotic and ant-inflammatory effects of minocycline on hair cells. Current evidence suggests that minocycline inhibition of p38 MAP kinase phosphorylation and inhibition of caspases are possible. On balance, we believe that reporting our results without precise mechanism data is consistent with the sentiment of the public request for publication of even negative minocycline efficacy studies, which may have impeded progress in this field [45]. 


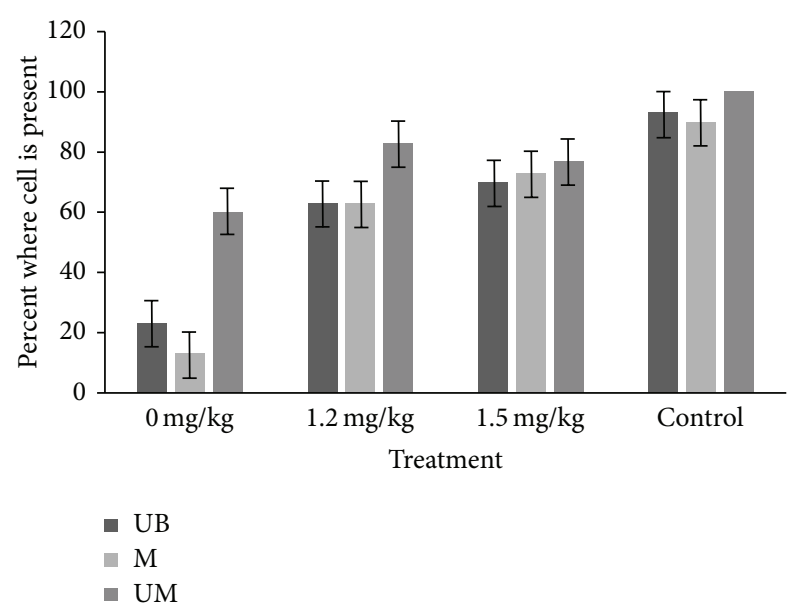

(a) Inner hair cells and treatment

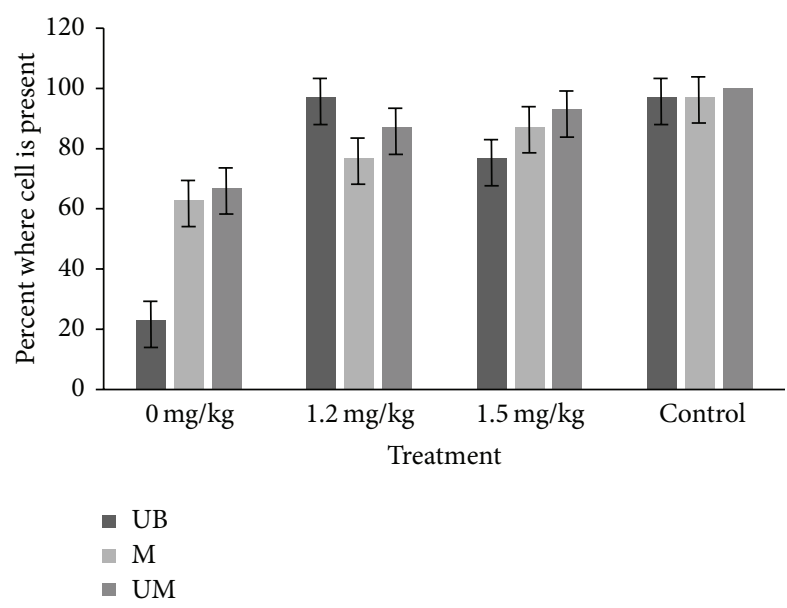

(c) Outer hair cell row 2 and treatment

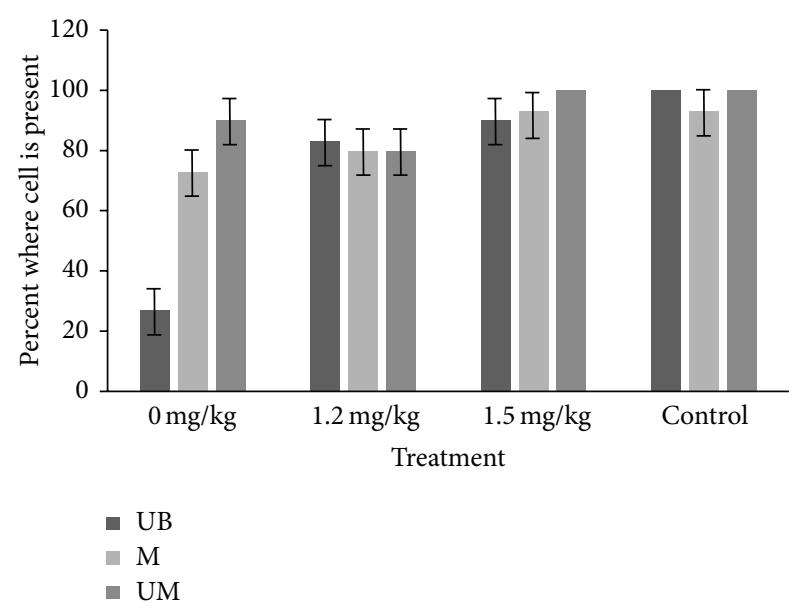

(b) Outer hair cell row 1 and treatment

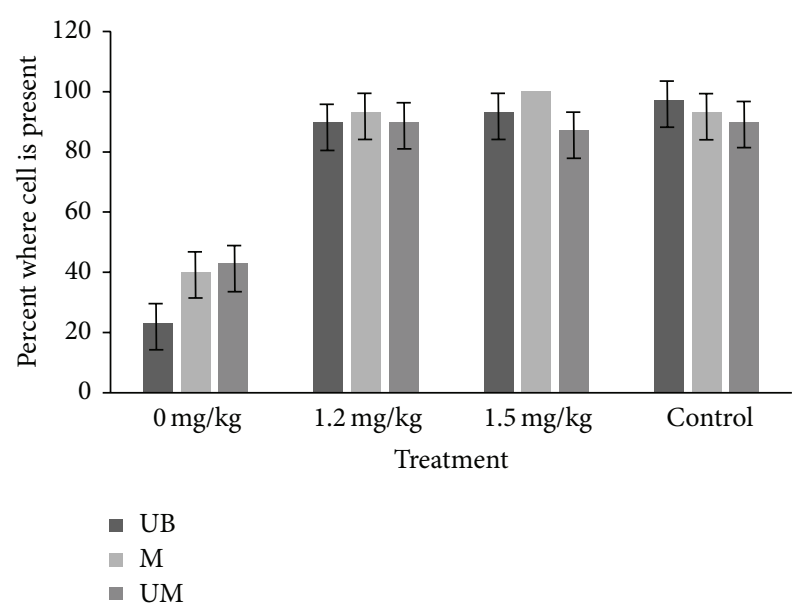

(d) Outer hair cell row 3 and treatment

FIGURE 4: Presence of different cell types was scored in the organ of Corti for each minocycline concentration left ear treatment group in three cochlear turns. Ten sections for each cochlear turn were evaluated for each of three animals per treatment $(0 \mathrm{mg} / \mathrm{kg} .1 .2 \mathrm{mg} / \mathrm{kg}, 1.5 \mathrm{mg} / \mathrm{kg}$ minocycline with neomycin) and no neomycin or minocycline control, such that each turn is represented by a total of 30 sections. The percent of sections where each cell type was present and the corresponding cochlear turns (upper basal UB, middle M, and upper middle UM) are indicated. Error bars represent standard deviation of the proportion of sections where the cell type is present, an absent error bar indicates that all sections contained the cell type. (a) shows percent inner hair cells (IHC) present and (b), (c), and (d) show percent outer hair cell $(\mathrm{OHC})$ rows 1, 2, and 3 present, respectively. Dieters cell rows 1, 2, and 3 showed a similar pattern to the outer hair cells (not shown).

We did, however, find in pilot studies that there was no difference between wild type and Bax knockout noise induced hearing loss and, therefore, hair cell apoptosis. This lack of protection due to noise exposure in Bax knockout mice is consistent with Bak protein perhaps being the dominant of these two proapoptosis proteins in mitochondrial apoptosis in hair cells. In support of this, others have reported that in age-related hearing loss studies that there was no difference between middle age wild type and middle age Bax knockout mice in their ABR thresholds, while Bak knockout mice had lower thresholds and this correlated with greater density of SGNs and number of outer hair cells only in the Bak knockout mice [46]. Furthermore, several of their other experiments indicated that reactive oxygen species were responsible for apoptosis and that Bak deficiency prevented cell death.
Therefore, Bax does not appear to be capable of compensating for lack of Bak expression in age-related hearing loss [46].

Clinically, the use of minocycline for hearing preservation would be limited by its partial efficacy, likely a reflection of redundant apoptosis pathways in hair cells and potential species differences. Several other agents that may partially protect hearing are being examined in animal models of chemical ototoxicity and noise mediated deafness [28]. For example, the known free radical scavenger Allopurinol has been found to provide short term protection from hearing loss in guinea pigs [47, 48]. Combination therapies including minocycline could potentially convey synergistic otoprotection in humans. Also, optimal dosages and routes of administration, including intratympanic injection, have not been investigated. In our model minocycline protection 
effectiveness had been reached at $1.2 \mathrm{mg} / \mathrm{kg}$. Dosages in other experimental models have demonstrated that efficacy of minocycline in terms of reduced cell death varies widely. For example, in vitro, $0.1 \mu \mathrm{M}$ minocycline has been shown to inhibit the apoptosis promoting enzyme activity of poly (ADP-ribose) polymerase 1 (PARP-1) and confer $85 \%$ increased survival of neurons in culture, and $5 \mathrm{mg} / \mathrm{kg}$ intraperitoneal minocycline delayed cell death and inhibited caspase- 1 and caspase- 3 expression in the brains of a mouse model of Huntington's disease [49]. In humans $3-10 \mathrm{mg} / \mathrm{kg}$ intravascular doses of minocycline are being evaluated for use in stroke treatment [50]. It should be kept in mind that some applications of minocycline that appear promising in animal models, for example, Huntington's disease [51], may not proceed to human use [52].

Often traumatic brain injury is associated with sound overpressure damage to the cochlea, such as munitions explosions, which can lead to permanent hearing threshold elevation. Such noise induced hearing loss is primarily by apoptosis, and the medical use of minocycline to ameliorate hearing loss could be tested, based on our demonstration of minocycline amelioration of neomycin induced hearing loss. In addition, combination use of minocycline with aminoglycoside antibiotics for bacterial infection could also be evaluated as a means of ameliorating ototoxic hearing loss.

\section{Conflict of Interests}

There is no conflict of interests or financial disclosures.

\section{Acknowledgments}

This study was supported by the E.R. Capita Foundation and the Department of Otolaryngology-Head and Neck Surgery, Feinberg School of Medicine, Northwestern University.

\section{References}

[1] A. Forge and J. Schacht, "Aminoglycoside antibiotics," Hearing Research, vol. 197, pp. 11-18, 2000.

[2] O. W. Guthrie, "Aminoglycoside induced ototoxicity," Toxicology, vol. 249, no. 2-3, pp. 91-96, 2008.

[3] A. Forge and J. Schacht, "Aminoglycoside antibiotics," Audiology and Neuro-Otology, vol. 5, no. 1, pp. 3-22, 2000.

[4] A. Forge and L. Li, "Apoptotic death of hair cells in mammalian vestibular sensory epithelia," Hearing Research, vol. 139, no. 1-2, pp. 97-115, 2000.

[5] L. P. Rybak and V. Ramkumar, "Ototoxicity," Kidney International, vol. 72, no. 8, pp. 931-935, 2007.

[6] H. Stupp, K. Kupper, and F. Lagler, "Inner ear concentrations and ototoxicity of different antibiotics in local and systemic application," Audiology, vol. 12, no. 5-6, pp. 350-363, 1973.

[7] R. Janknegt, "Aminoglycoside therapy. Current use and future prospects," Pharmaceutisch Weekblad-Scientific Edition, vol. 12, no. 3, pp. 81-90, 1990.

[8] T. T. Yoshikawa, "Proper use of aminoglycosides," American Family Physician, vol. 21, no. 5, pp. 125-130, 1980.

[9] M. I. Wright, "Ototoxicity: a consideration of routes and mechanisms of hair cell damage associated with certain antibiotics and diuretics," Proceedings of the Royal Society of Medicine, vol. 66, no. 2, pp. 189-193, 1973.

[10] S. Kossowski, J. Gieldanowski, and Z. Ziemski, "Experimental studies on the ototoxicity of certain antibiotics," Archivum Immunologiae et Therapiae Experimentalis, vol. 12, pp. 402-406, 1964.

[11] W. H. Harrison, "Ototoxicity of dihydrostreptomycin," Quarterly Bulletin of the Northwestern University, vol. 28, no. 3, pp. 271-273, 1954.

[12] J. E. Hawkins Jr. and M. H. Lurie, "The ototoxicity of streptomycin," Transactions of the American Otological Society, vol. 40, pp. 133-153, 1952.

[13] J. Schacht, "Biochemical basis of aminoglycoside ototoxicity," Otolaryngologic Clinics of North America, vol. 26, no. 5, pp. 845856, 1993.

[14] M. D. Rizzi and K. Hirose, "Aminoglycoside ototoxicity," Current Opinion in Otolaryngology \& Head \& Neck Surgery, vol. 15, no. 5, pp. 352-357, 2007.

[15] E. Selimoglu, "Aminoglycoside-induced ototoxicity," Current Pharmaceutical Design, vol. 13, no. 1, pp. 119-126, 2007.

[16] M. Suzuki, M. Ushio, and T. Yamasoba, “Time course of apoptotic cell death in guinea pig cochlea following intratympanic gentamicin application," Acta Oto-Laryngologica, vol. 128, no. 7, pp. 724-731, 2008.

[17] H. H. Bo, W. Guo, P. Y. Wang, D. Henderson, and C. J. Si, "Intense noise-induced apoptosis in hair cells of guinea pig cochleae," Acta Oto-Laryngologica, vol. 120, no. 1, pp. 19-24, 2000

[18] T. Huang, A. G. Cheng, H. Stupak et al., "Oxidative stressinduced apoptosis of cochlear sensory cells: otoprotective strategies," International Journal of Developmental Neuroscience, vol. 18, no. 2-3, pp. 259-270, 2000.

[19] P. P. Lefebvre, B. Malgrange, F. Lallemend, H. Staecker, G. Moonen, and T. R. Van De Water, "Mechanisms of cell death in the injured auditory system: otoprotective strategies," Audiology and Neuro-Otology, vol. 7, no. 3, pp. 165-170, 2002.

[20] T. R. van de Water, F. Lallemend, A. A. Eshraghi et al., "Caspases, the enemy within, and their role in oxidative stress-induced apoptosis of inner ear sensory cells," Otology \& Neurotology, vol. 25, no. 4, pp. 627-632, 2004.

[21] A. Zine and T. R. van de Water, “The MAPK/JNK signalling pathways offers potential therapeutic targets for the prevention of acquired deafness," Current Drug Targets-CNS and Neurological Disorders, vol. 3, no. 4, pp. 325-332, 2004.

[22] A. A. Eshraghi and T. R. Van De Water, "Cochlear implantation trauma and noise-induced hearing loss: apoptosis and therapeutic strategies," The Anatomical Record, Part A: Discoveries in Molecular, Cellular, and Evolutionary Biology, vol. 288, no. 4, pp. 473-481, 2006.

[23] C. T. Dinh and T. R. van de Water, "Blocking pro-cell-death signal pathways to conserve hearing," Audiology and Neurotology, vol. 14, no. 6, pp. 383-392, 2009.

[24] A. G. Cheng, L. L. Cunningham, and E. W. Rubel, "Hair cell death in the avian basilar papilla: characterization of the in vitro model and caspase activation," Journal of the Association for Research in Otolaryngology, vol. 4, no. 1, pp. 91-105, 2003.

[25] E. M. Priuska and J. Schacht, "Formation of free radicals by gentamicin and iron and evidence for an iron/gentamicin complex," Biochemical Pharmacology, vol. 50, no. 11, pp. 1749$1752,1995$. 
[26] G. Kroemer and J. C. Reed, "Mitochondrial control of cell death," Nature Medicine, vol. 6, no. 5, pp. 513-519, 2000.

[27] A. K. F. Liou, R. S. Clark, D. C. Henshall, X.-M. Yin, and J. Chen, "To die or not to die for neurons in ischemia, traumatic brain injury and epilepsy: a review on the stress-activated signaling pathways and apoptotic pathways," Progress in Neurobiology, vol. 69, no. 2, pp. 103-142, 2003.

[28] E. D. Lynch and J. Kil, "Compounds for the prevention and treatment of noise-induced hearing loss," Drug Discovery Today, vol. 10, no. 19, pp. 1291-1298, 2005.

[29] D. A. Cotanche, "Genetic and pharmacological intervention for treatment/prevention of hearing loss," Journal of Communication Disorders, vol. 41, no. 5, pp. 421-443, 2008.

[30] K. Maier, D. Merkler, J. Gerber et al., "Multiple neuroprotective mechanisms of minocycline in autoimmune CNS inflammation," Neurobiology of Disease, vol. 25, no. 3, pp. 514-525, 2007.

[31] S. Matsuki, Y. Iuchi, Y. Ikeda, I. Sasagawa, Y. Tomita, and J. Fujii, "Suppression of cytochrome c release and apoptosis in testes with heat stress by minocycline," Biochemical and Biophysical Research Communications, vol. 312, no. 3, pp. 843-849, 2003.

[32] M. Michaelis, M. C. Kleinschmidt, H. W. Doerr, and J. Cinatl Jr., "Minocycline inhibits West Nile virus replication and apoptosis in human neuronal cells," Journal of Antimicrobial Chemotherapy, vol. 60, no. 5, pp. 981-986, 2007.

[33] R. Pi, W. Li, N. T. K. Lee et al., "Minocycline prevents glutamateinduced apoptosis of cerebellar granule neurons by differential regulation of p38 and Akt pathways," Journal of Neurochemistry, vol. 91, no. 5, pp. 1219-1230, 2004.

[34] S. M. Richardson-Burns and K. L. Tyler, "Minocycline delays disease onset and mortality in reovirus encephalitis," Experimental Neurology, vol. 192, no. 2, pp. 331-339, 2005.

[35] A. N. Sapadin and R. Fleischmajer, "Tetracyclines: nonantibiotic properties and their clinical implications," Journal of the American Academy of Dermatology, vol. 54, no. 2, pp. 258-265, 2006.

[36] T. M. Scarabelli, A. Stephanou, E. Pasini et al., "Minocycline inhibits caspase activation and reactivation, increases the ratio of XIAP to smac/DIABLO, and reduces the mitochondrial leakage of cytochrome $\mathrm{C}$ and smac/DIABLO," Journal of the American College of Cardiology, vol. 43, no. 5, pp. 865-874, 2004.

[37] X. Wei, L. Zhao, J. Liu, R. C. Dodel, M. R. Farlow, and Y. $\mathrm{Du}$, "Minocycline prevents gentamicin-induced ototoxicity by inhibiting p38 MAP kinase phosphorylation and caspase 3 activation," Neuroscience, vol. 131, no. 2, pp. 513-521, 2005.

[38] S. Reagan-Shaw, M. Nihal, and N. Ahmad, "Dose translation from animal to human studies revisited," The FASEB Journal, vol. 22, no. 3, pp. 659-661, 2008.

[39] C.-P. Richter, R. Bayon, A. D. Izzo et al., "Optical stimulation of auditory neurons: effects of acute and chronic deafening," Hearing Research, vol. 242, no. 1-2, pp. 42-51, 2008.

[40] M. Pearce, C.-P. Richter, and M. A. Cheatham, "A reconsideration of sound calibration in the mouse," Journal of Neuroscience Methods, vol. 106, no. 1, pp. 57-67, 2001.

[41] E. Corbacella, I. Lanzoni, D. Ding, M. Previati, and R. Salvi, "Minocycline attenuates gentamicin induced hair cell loss in neonatal cochlear cultures," Hearing Research, vol. 197, no. 1-2, pp. 11-18, 2004.

[42] A. G. Cheng, L. L. Cunningham, and E. W. Rubel, "Mechanisms of hair cell death and protection," Current Opinion in Otolaryngology and Head and Neck Surgery, vol. 13, no. 6, pp. 343-348, 2005.
[43] H.-S. Kim and Y.-H. Suh, "Minocycline and neurodegenerative diseases," Behavioural Brain Research, vol. 196, no. 2, pp. 168179, 2009.

[44] S. Cornet, B. Spinnewyn, S. Delaflotte et al., "Lack of evidence of direct mitochondrial involvement in the neuroprotective effect of minocycline," European Journal of Pharmacology, vol. 505, no. 1-3, pp. 111-119, 2004.

[45] E. Diguet, C. E. Gross, F. Tison, and E. Bezard, "Rise and fall of minocycline in neuroprotection: need to promote publication of negative results," Experimental Neurology, vol. 189, no. 1, pp. $1-4,2004$.

[46] S. Someya, J. Xu, K. Kondo et al., "Age-related hearing loss in C57BL/6J mice is mediated by Bak-dependent mitochondrial apoptosis," Proceedings of the National Academy of Sciences of the United States of America, vol. 106, no. 46, pp. 19432-19437, 2009.

[47] A. Franzé, L. Sequino, C. Saulino, G. Attanasio, and E. Marciano, "Effect over time of allopurinol on noise-induced hearing loss in guinea pigs: efecto en el tiempo del alopurinol sobre la hipoacusia inducida por ruido en cobayos," International Journal of Audiology, vol. 42, no. 4, pp. 227-234, 2003.

[48] M. D. Seidman, B. G. Shivapuja, and W. S. Quirk, "The protective effects of allopurinol and superoxide dismutase on noise- induced cochlear damage," Otolaryngology-Head and Neck Surgery, vol. 109, no. 6, pp. 1052-1056, 1993.

[49] M. Chen, V. O. Ona, M. Li et al., "Minocycline inhibits caspase1 and caspase- 3 expression and delays mortality in a transgenic mouse model of Huntington disease," Nature Medicine, vol. 6, no. 7, pp. 797-801, 2000.

[50] S. C. Fagan, J. L. Waller, F. T. Nichols et al., "Minocycline to improve neurologic outcome in stroke (MINOS): a dosefinding study," Stroke, vol. 41, no. 10, pp. 2283-2287, 2010.

[51] M. Sancho, A. E. Herrera, A. Gortat et al., "Minocycline inhibits cell death and decreases mutant Huntingtin aggregation by targeting Apaf-1," Human Molecular Genetics, vol. 20, no. 18, pp. 3545-3553, 2011.

[52] M. Cudkowicz and The Huntington Study Group DOMINO Investigators, "A futility study of minocycline in huntington's disease," Movement Disorders, vol. 25, no. 13, pp. 2219-2224, 2010. 


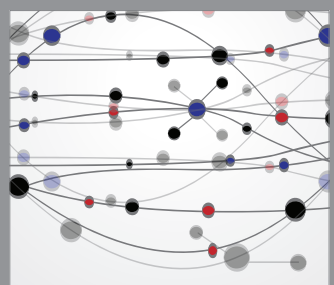

The Scientific World Journal
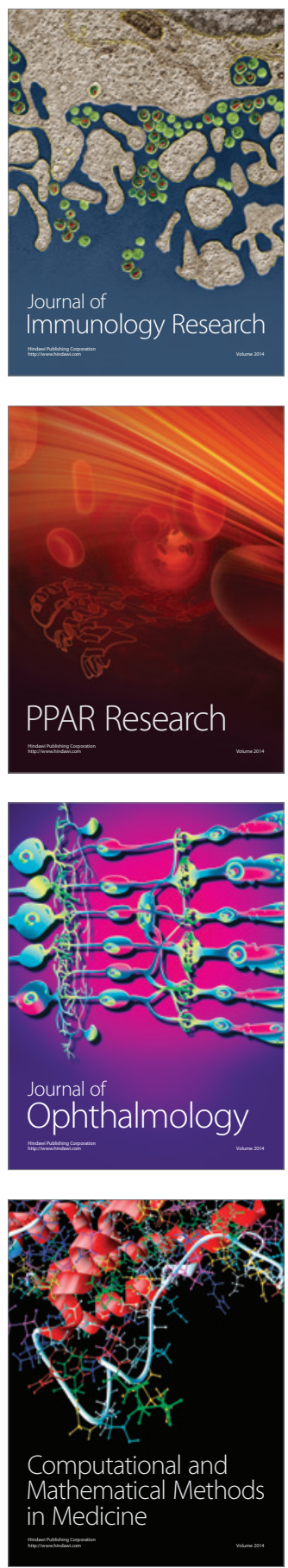

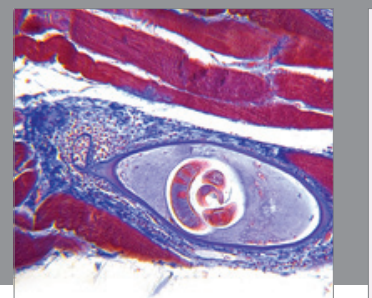

Gastroenterology

Research and Practice
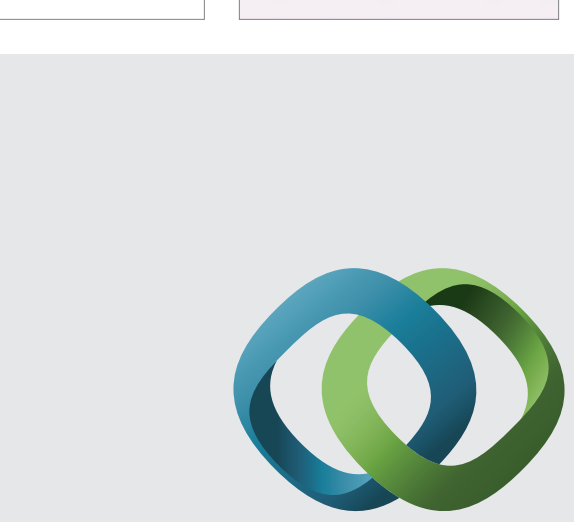

\section{Hindawi}

Submit your manuscripts at

http://www.hindawi.com
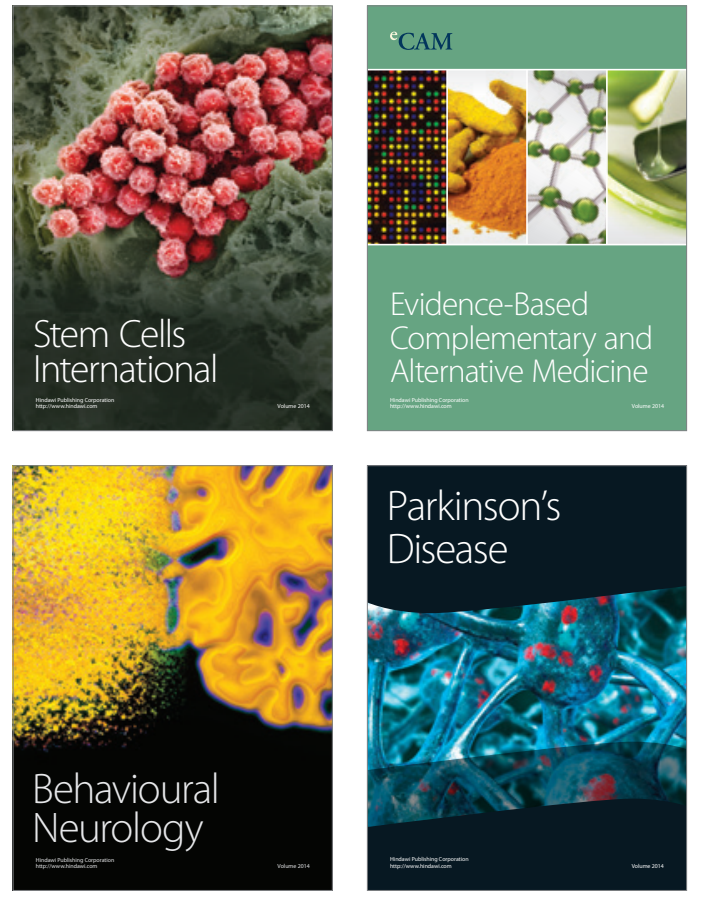
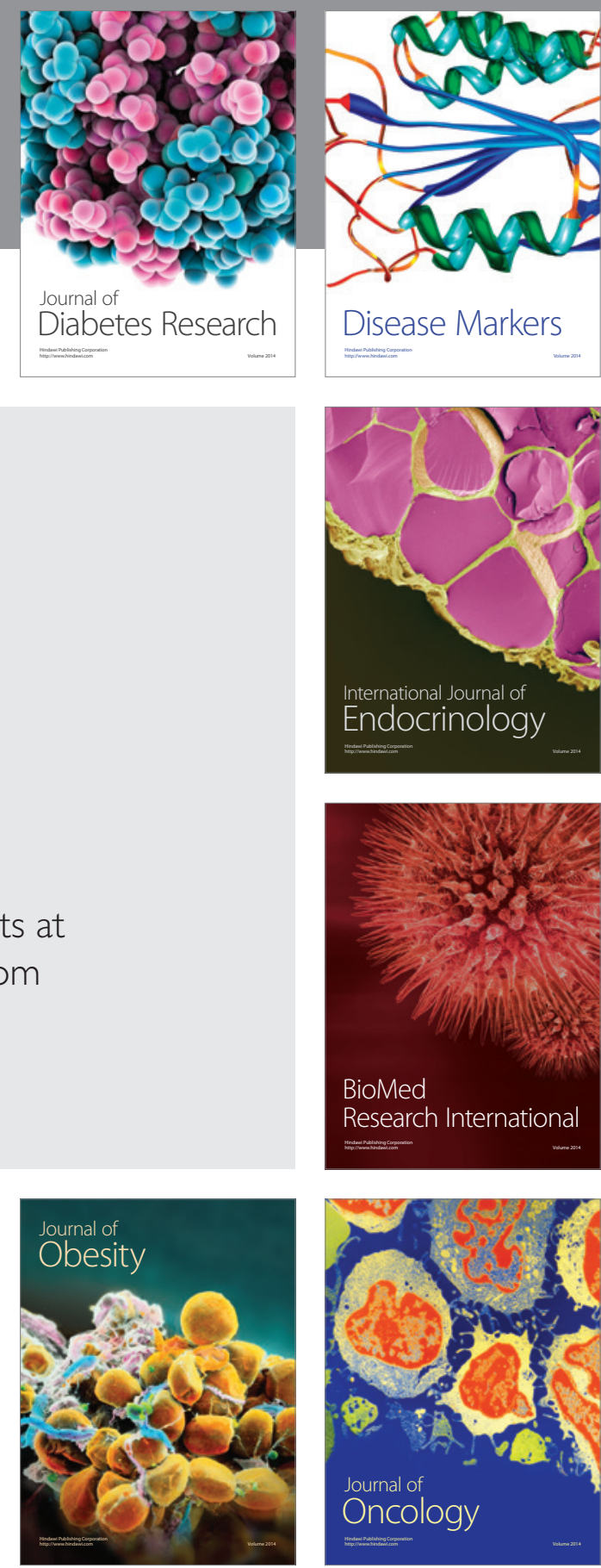

Disease Markers
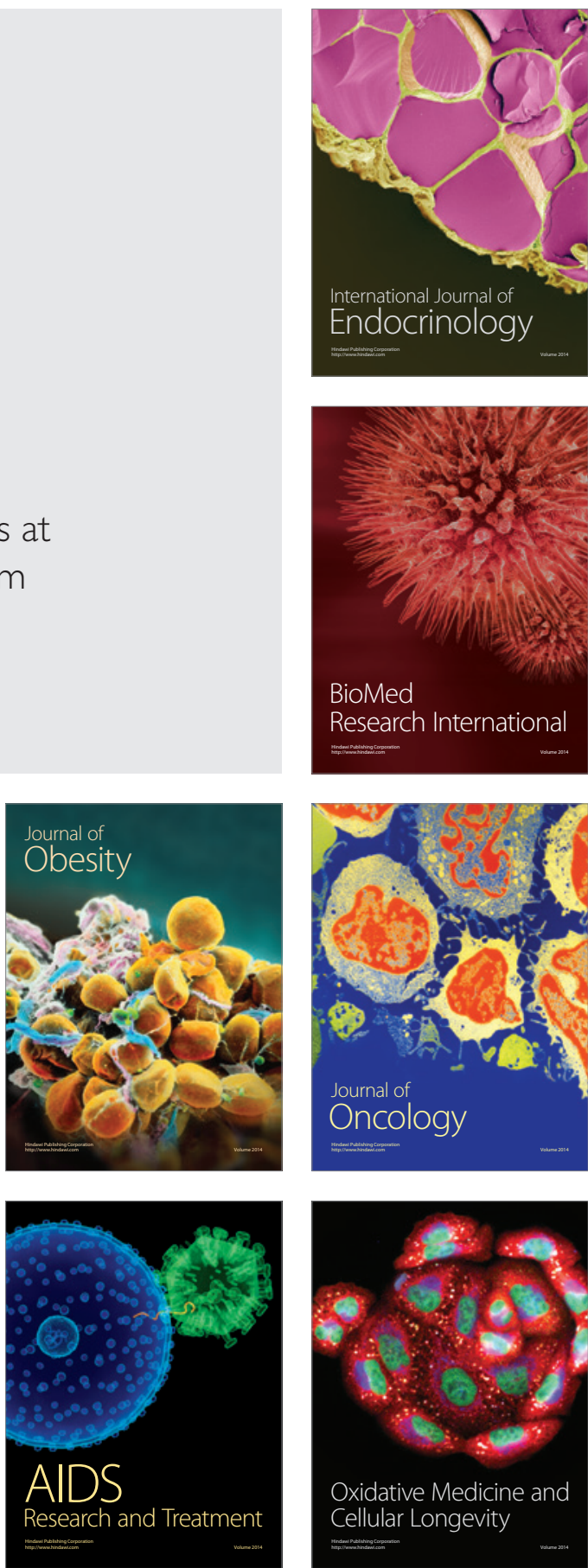